\title{
The Oxford History of the Irish Book, Volume IV : the Irish Book in English (1800-1891)
}

\section{Sylvie Mikowski}

\section{(2) OpenEdition}

\section{Journals}

Édition électronique

URL : https://journals.openedition.org/etudesirlandaises/3230

DOI : 10.4000/etudesirlandaises.3230

ISSN : 2259-8863

\section{Éditeur}

Presses universitaires de Caen

\section{Édition imprimée}

Date de publication : 30 octobre 2012

Pagination : $170-172$

ISBN : 978-7535-2158-2

ISSN : 0183-973X

\section{Référence électronique}

Sylvie Mikowski, «The Oxford History of the Irish Book, Volume IV : the Irish Book in English

(1800-1891) », Études irlandaises [En ligne], 37-2 | 2012, mis en ligne le 30 octobre 2012, consulté le 26 juillet 2022. URL : http://journals.openedition.org/etudesirlandaises/3230 ; DOI : https://doi.org/ 10.4000/etudesirlandaises.3230

Ce document a été généré automatiquement le 26 juillet 2022.

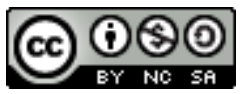

Creative Commons - Attribution - Pas d'Utilisation Commerciale - Partage dans les Mêmes Conditions 4.0 International - CC BY-NC-SA 4.0

https://creativecommons.org/licenses/by-nc-sa/4.0/ 


\title{
The Oxford History of the Irish Book, Volume IV : the Irish Book in English (1800-1891)
}

\author{
Sylvie Mikowski
}

\section{RÉFÉRENCE}

The Oxford History of the Irish Book, Volume IV : the Irish Book in English (1800-1891), edited by James H. Murphy, OUP, 2011, 732 p., ISBN 978-0-19-818731-8

1 The Oxford History of the Irish Book est une entreprise monumentale initiée à la fin des années 1990 par les professeurs Robert Welch et Brian Walker de l'Université d'Ulster et qui inclura un total de cinq volumes. Comme l'a démontré Eric Hobsbawm, la culture de l'imprimé joue un rôle essentiel dans la circulation des idées à l'origine des grands bouleversements historiques, d'où l'intérêt de retracer les étapes de son développement. Les différents auteurs de cet ouvrage collectif viennent d'horizons variés: ils sont bien sûr historiens, mais aussi géographes, conservateurs de bibliothèques, musicologues, critiques littéraires, spécialistes des religions. On remarquera la période réduite abordée dans ce volume et les dates qui ont été choisies pour la démarquer: d'une part 1800, date de l'inclusion de l'Irlande dans l'Empire britannique à la suite de l'Acte d'Union, d'autre part 1891, date de la mort de Parnell et de la création de la Irish Literary Society par W.B. Yeats et donc début de la Renaissance celtique. En raison de la disparition du parlement de Dublin, qui fit perdre à l'Irlande toute indépendance politique, et surtout de la Grande Famine des années 1845 qui décima sa population, cette période de l'histoire irlandaise est souvent considérée comme une sorte de trou noir pour la vie intellectuelle, culturelle et artistique de ce pays, alors qu'elle fut synonyme au contraire pour les grandes puissances européennes d'expansion territoriale, de croissance économique et d'innovation artistique, scientifique et technologique. The Oxford History of the Irish Book est une impressionnante somme d'érudition, amassée par de véritables archéologues du savoir, 
qui contribue à corriger cette vision caricaturale et fausse. En révélant au grand jour et sous des aspects les plus divers un fourmillement d'activité intellectuelle ou artistique, en rappelant de grands noms oubliés, l'ouvrage démontre, si besoin était encore, que l'Irlande n'était évidemment pas, entre 1800 et 1891, un îlot isolé au milieu de nulle part, mais bénéficiait d'échanges permanents avec le reste de l'Europe ; que les idées agitées à la fin du dix-huitième siècle par des sociétés comme celle des United Irishmen ne furent pas annihilées par l'Acte d'Union; que celles qui donnèrent naissance à la Renaissance celtique avaient bien sûr germé tout au long du siècle. Certes, celui-ci démarre sous de mauvais auspices pour le livre en Irlande, puisqu'à la suite de l'Acte d'Union, la loi sur les droits d'auteurs, qui jusque-là ne s'appliquait pas dans l'île, s'étend à présent à toutes les provinces de l'empire, mettant fin au commerce lucratif des reproductions gratuites et illimitées d'ouvrages de toutes sortes, destinées aussi bien au marché intérieur qu'à l'exportation, et qui avait assuré au dix-huitième siècle la prospérité de nombreux éditeurs ou libraires irlandais. Les taxes sur la presse limitent aussi la circulation des périodiques.

2 Mais de nombreuses évolutions de la société irlandaise pendant cette période permettent un rebond de l'édition et de la distribution de l'imprimé : le degré d'alphabétisation de la population augmente, ainsi que la maîtrise de l'anglais, donnant accès au plus grand nombre à des formes plus ou moins sophistiquées de littérature. Niall ó Ciosáin par exemple souligne que, comme dans plusieurs autres grands pays européens comme la France ou l'Allemagne, les paysans irlandais se procuraient des almanachs répertoriant les fêtes et les foires, mais aussi des livres de colportage, des pamphlets religieux ou politiques, ainsi que des recueils de ballades. C'est d'ailleurs pour mieux surveiller ces lectures jugées potentiellement subversives ou immorales que des sociétés philanthropiques, dont la plus connue, la Kildare Place Society, est mentionnée dans plusieurs chapitres de cet ouvrage, subventionnèrent des publications bien-pensantes et les distribuèrent dans les écoles ou par le biais de bibliothèques également subventionnées. Le développement de l'éducation publique contribua aussi à la diffusion des livres, les programmes nationaux requérant la publication d'ouvrages spécifiques. Les antagonismes entre les deux églises dominantes, catholique et protestante, donnèrent naissance à un grand nombre d'ouvrages polémiques. La pensée victorienne dominante, en se préoccupant d'inculquer au plus grand nombre ses codes moraux et sexuels rigoureux, entraîna en Irlande comme dans le reste de l'Empire la publication de multiples conduct books pour les jeunes filles, mais aussi de livres pour enfants, ou sur l'éducation des enfants, Maria Edgeworth étant l'une des plus éminentes représentantes de cette tendance. Mais l'imprimé servit à diffuser aussi des idées plus contestataires, comme le montre l'institution des Repeal Reading Rooms destinées à répandre les idées des Young Irelanders. Les journaux et périodiques, même s'ils ne durent pas toujours très longtemps, se multiplient tout au long du siècle. Parmi eux se distinguent The Nation, ou The Dublin University Magazine, successivement dirigé par Charles Lever et Joseph Sheridan LeFanu et dans lequel ils publièrent leurs propres romans en feuilletons, mais aussi ceux de William Carleton et de Isaac Butt. Il faut mentionner aussi The Dublin Penny Magazine qui s'efforçait de valoriser le patrimoine culturel irlandais, et encore The Irish Builder qui connut un très grand succès et informait ses lecteurs sur les derniers développements de la technologie ou des progrès des méthodes d'agriculture. Quels auteurs lisait-on en Irlande au dix-neuvième siècle ? Comme ailleurs dans l'Empire, Walter Scott, Dickens ou Shakespeare étaient de grands favoris, mais W. Carleton, C. Lever, les frères Banim, 
Gerald Griffith connurent de vrais succès, même s'ils n'étaient pas toujours publiés par des éditeurs irlandais, tout comme Lady Morgan. Il y eut pourtant de grands éditeurs irlandais, comme James Duffy à Dublin, ou Marcus Ward à Belfast, qui surent faire baisser le prix des livres pour les rendre accessibles au plus grand nombre. A côté de cette culture populaire vivante se développait aussi une culture savante, nourrie en particulier par le mouvement antiquarian, mené par George Petrie, Sir William Wilde, John O'Donovan ou Eugene Curry, et qui au sein de la Royal Irish Academy entreprit de recouvrer le patrimoine national jusque-là enfoui, comme le montre la publication des Annals of the Kingdom of Ireland by the Four Masters en édition bilingue anglais-gaélique. Le chapitre fascinant consacré à l'impression et la diffusion des cartes d'état-major, les fameuses Ordnance Surveys de 1824, montre l'étendue du champ de recherche embrassé par l'histoire de l'imprimé. De plus, comme la plupart des chapitres de cet ouvrage indispensable, il révèle toute l'ambivalence du rattachement de l'Irlande à l'Empire à la suite de l'Acte d'Union : l'union fut certes synonyme de déclin, mais contribua à inclure l'Irlande dans la sphère idéologique victorienne, avec son obsession d'imprégner le plus grand nombre d'esprits de sa morale et de ses codes rigides, mais aussi sa passion pour la science et le savoir ; par ailleurs, le sentiment de déclin qui suivit l'union donna vite lieu à une revendication identitaire très vigoureuse, qui suscita également une quête de savoir et d'exploration du passé de l'Irlande. Celle-ci allait déboucher d'abord sur le mouvement de la Renaissance celtique, puis sur les luttes de libération nationale. Ce que ne manquera sans doute pas de souligner le volume VI de la collection.

\section{AUTEURS}

\section{SYLVIE MIKOWSKI}

Université de Reims-Champagne Ardennes 